\title{
Intervention to Reduce Needle Stick Injuries
}

\author{
Tun Fizi A, Maygala A, Suzana K, Yogeswari A, Nishazini MB and Zainah J \\ KPJ Seremban Specialist Hospital, Seremban, Negeri Sembilan
}

\section{ABSTRACT}

Introduction: Healthcare workers face the risk of infection from potentially deadly diseases from the use of unsafe needles every day. It has been estimated that over 350,000 needlestick and sharps related injuries occur annually with an average of 1,000 infections annually and over 100 deaths by the CDC (Centers for Disease Control \& Prevention). It has been reported that 0.6 cases in average of needle stick injury incident occurred in KPJ Seremban almost every month in 2008. Analysis was done and it was that found that the majority of cases were due to failure to adhere to universal precautions. Materials and Methods: A retrospective study was done (January to December 2008). Data was collected from reviewed incidence reports. Statistics showed that needle stick injuries occurred after a procedure and during disposal of used needles. We then introduced several measures with these aims; to inculcate 'Safety Culture' among healthcare workers through quality training, to ensure that all newly qualified healthcare workers are well trained in handling sharp devices, to reduce the incidence of needlestick injuries, to do effective monitoring audit, to convey knowledge to healthcare workers on safety practices by Infection control team. These strategies included; High quality education and training to all staffs conducted continuously, identifying those at risk, introduce safer medical devices - using of Angiocath for setting IV line and needle-less injection port and providing for a secure work environment. Results: 1) Needle stick injury cases reduce 65\% as compared to last year. 2) Through surveys and questionnaires, 95\% of healthcare workers understand and adhere to universal precautions in 2009 as compared 30\% in previous year. 3) Number training conducted increased from 7days in year 2008 to 21 days in year 2009. Conclusion: Collaborative and participative approaches are helpful in reducing the transmission of blood borne pathogens and other sharps-related injuries.

KEYWORDS: Needle-stick injury, prevention, strategies

Corresponding author; Nishazini bt Mohd Basir, Quality Assurance Officer KPJ Seremban Specialist Hospital, Lot 6219 \& 6220, Jalan Toman Satu, Kemayan Square, 70200 Seremban, Negeri Sembilan e-mail: nisha@ssh.kpjhealth.com.my 